\title{
Sciendo
}

RESEARCH PAPERS FACULTY OF MATERIALS

SCIENCE AND TECHNOLOGY IN TRNAVA

SLOVAK UNIVERSITY OF TECHNOLOGY

IN BRATISLAVA

2021, Volume 29, Number 48

DOI 10.2478/rput-2021-0010

\section{DEGRADATION OF ELECTRICAL WIRE SHEATHS BY UV RADIATION}

\author{
Alica PASTIEROVÁ ${ }^{1}$, Peter GODOVČIN ${ }^{1}$ \\ ${ }^{1}$ SLOVAK UNIVERSITY OF TECHNOLOGY IN BRATISLAVA \\ FACULTY OF MATERIALS SCIENCE AND TECHNOLOGY IN TRNAVA \\ INSTITUTE OF INTEGRATED SAFETY \\ Ulica JÁnA BotTu 2781/25, 91724 TRNAVA, SLOVAK REPUBLIC \\ e-mail: alica.pastierova@stuba.sk, peter.godovcin@stuba.sk \\ Received 28 April 2021, Accepted 26 May 2021, Published 20 July 2021
}

\begin{abstract}
The objective of this manuscript is to report experimental results concerning the effect of accelerated UV-C ageing on the properties of samples of halogen-free sheaths of power cables. Two samples of halogen free sheaths of power cables of Vuki a.s. CHKE-V E3O and Nexans 273-K3 HERP/CWB/2SZH were studied after exposition on the UV-C radiation in a closed chamber. Degradation was monitored by the change in infrared spectra of the samples, their hardness and colour. Based on the observed changes, it can be argued that exposure to the $U V$ $C$ radiation affects the observed properties on the surface of the studied samples. All the observed changes were due to the rupture of the bonds towing to the absorption of $U V-C$ radiation.
\end{abstract}

\section{Keywords}

Wire sheath, UV-C degradation, infrared spectra, hardness, decolouration

\section{INTRODUCTION}

Lifetime prediction of polymeric materials offers the benefit of isolating and identifying material failures against the fallouts of damage resulting in catastrophic harm. Therefore, accurate prediction of the service life of material is very important in terms of safety, especially considering the elastomeric materials used in many fields, especially for electrical wires [1]. For electrical equipment such as cables, UV resistance is an important factor. When polymeric material is exposed to ultraviolet (UV) light, it degrades while losing its mechanical properties. Owing to the chain scission or chemical cross-linking, the mechanical properties of the polymer changes when subjected to UV radiations, which causes the photo-degradation of the polymer. Hence, a solution to overcome this problem is urgently needed.

As ultraviolet (UV) radiation consists of photons with high energy relative to visible light, it can cause degradation in the form of physical and chemical changes in susceptible materials. 
Ultraviolet radiation is divided into three bands: UV-A, 315 - $399 \mathrm{~nm}$; UV-B, 280 - $314 \mathrm{~nm}$; and UV-C, 100 - $279 \mathrm{~nm}[2]$.

Knowledge of the effects of the UV-C exposure on various materials is useful to the manufacturers and users of the UV-C disinfection and photochemical equipment. UV exposure can have a significant influence on the electrical cable insulation and sheathing. Cables likely to be exposed to UV light should either be designed of the UV resistant materials with a suitable carbon black content, or protected from exposure by a protective covering. It can make materials brittle, degrade their resistance, and induce colour change, thus affecting the lifetime of materials that are exposed to the weather [3].

UV-C radiation with wavelengths below $280 \mathrm{~nm}$ is potentially more harmful than UV-A and UV-B, but is mostly filtered by atmospheric gases, the most important of which is ozone. However, nowadays, when UV-C radiation is used as disinfection increasingly, study of the radiation on effect materials and their properties is very important [4].

The aim of this paper was to analyse the influence of the exposure to UV-C radiation on sheaths of a power cable made of hard ethylene propylene rubber by the FTIR spectroscopic infrared method, and decolouration analyses. The mechanical properties were analyses by the Shore hardness measurement.

\section{MATERIALS AND METHODS}

The effect UV-C radiation on halogen free sheaths of the Vuki a.s. CHKE-V E30 (orange colour) and the Nexans 273-K3 HERP/CWB/2SZH (green colour) power cables was studied within this investigation. Hard Grade Ethylene Propylene Rubber, popularly known as HEPR is a synthetic elastomer. Cables can be used in the fire hazard conditions, and can be installed on a flammable material. Cables have circuit integrity in fire for duration of $30 \mathrm{~min}$.

\section{UV exposure}

The UV aging was carried out in a UV chamber (Figure 1). Cover of samples cable were irradiated for 192 hours ( 8 days). All measurements were conducted after each 24 hours of the UV exposition. The ageing was performed under a temperature of $50^{\circ} \mathrm{C}$. As a source of UV-C radiation, we used four Philips TUV 15W.germicidal fluorescent lamps. The efficiency of the fluorescent lamp was $32 \%$. The UV-C radiation reached a power of $4.9 \mathrm{~W}$. The dimensions of the chamber were $440 \times 330 \times 420 \mathrm{~mm}$. Intensity of the radiance affected sample was $0.5665 \mathrm{Watt} / \mathrm{a}$ sample, and the surface area was $9 \mathrm{~cm}^{2}$ (front and back). Reflectivity of the inside surface was related to the reflectivity of polished aluminium at $92.5 \%$.

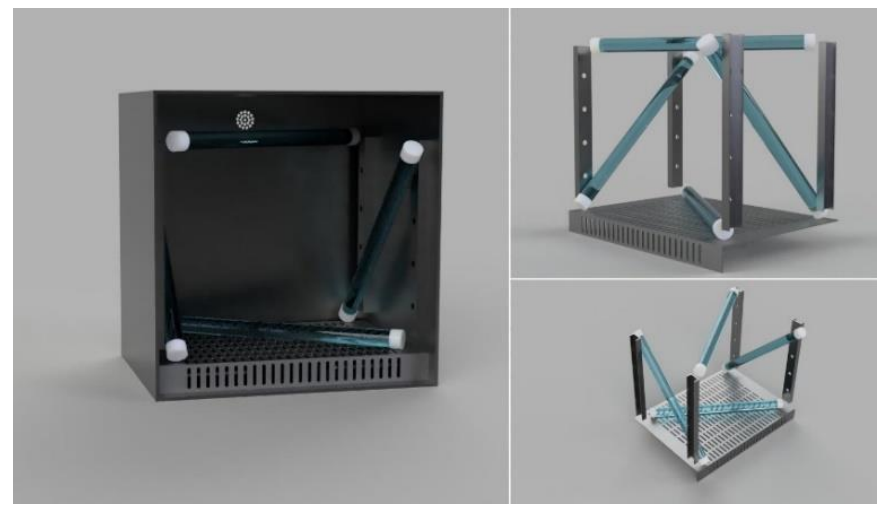

Figure 1 Digital model of UV chamber 


\section{FTIR analysis}

For FTIR (Varian FT-IR Spectrometer 660) analysis, samples of sheaths were directly applied to a diamante crystal of ATR (Pike Technology, GladiATR), and the resulting spectra were corrected for the background air absorbance. The spectra were recorded using a Varian Resolutions Pro, and the samples were measured in the region of $4000-400 \mathrm{~cm}^{-1}$; each spectrum was measured 48 times, at resolution of 4 .

\section{Discolouration analysis}

The 3nh NR200 colorimeter was used to determine the colour change before and after the UV exposure. This colorimeter uses a D65 light source and works in the CIE L*a*b* colour space. Ten measurements were performed on each tested sample.

The CIELAB, or CIE L* ${ }^{*}{ }^{*} b^{*}$, system is a three-dimensional colour-space consisting of three axes. The $L^{*}$ axis is a grayscale with values from 0 (black) to 100 (white). The $a^{*}$ is the $\mathrm{red} /$ green axis; positive and negative $a^{*}$ describe red and green values. The $b^{*}$ is the yellow/blue axis; positive and negative $b^{*}$ describe yellow and blue values [5].

The composite colour difference is denoted by $\Delta E^{*}{ }_{a b}$, which accounts for the changes of the $L^{*}, a^{*}$, and $b^{*}$ components, which can be calculated using the equation (1):

$$
\Delta E_{a b}^{*}=\left(\left(\Delta L^{*}\right)^{2}+\left(\Delta b^{*}\right)^{2}+\left(\Delta a^{*}\right)^{2}\right)^{1 / 2}
$$

$\Delta E^{*}$ value greater than one indicates colour difference observable by the human eye [6]. The human eye is only capable of detecting colour difference at certain thresholds. The minimal detectable difference is anywhere from $1-2.5 \Delta E^{*}$.

\section{The Shore Hardness}

The Shore Hardness is a characteristic value that is used predominantly for elastomers, soft rubbers and very soft plastics. The digital durometer for Shore A hardness with a static pressing load of $1.25 \mathrm{~kg}$ was used. Samples were measured before and after the exposure to UV-C radiation according ISO 868. On each tested sample, 10 measurements were performed. The measuring time lasted 15 seconds; after its expiration, we recorded the measured value.
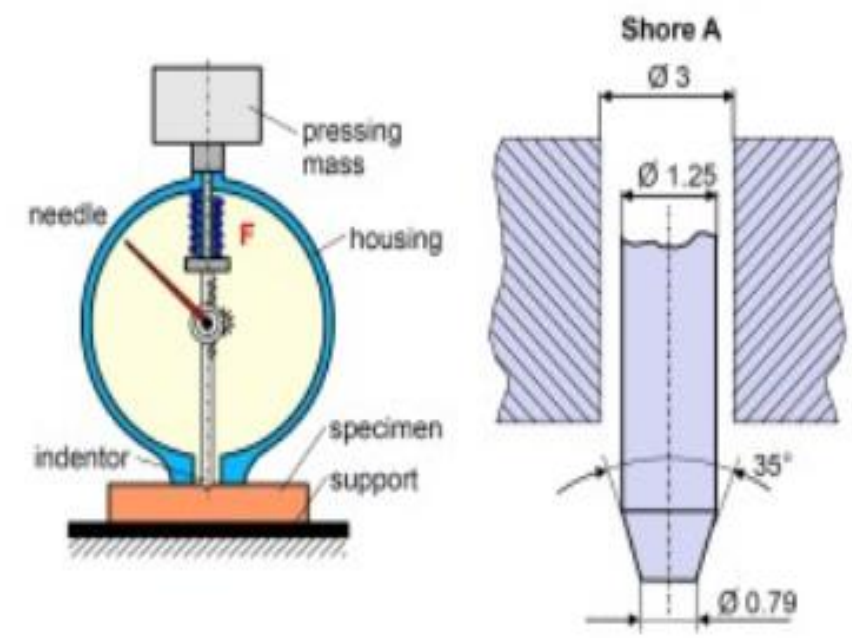

Figure 2 Hardness tester for Shore A and D as well as the Shore Indenter 


\section{RESULTS AND DISCUSION}

\section{FTIR analysis}

Both infrared spectra of CHKE-V E30 and Nexans 273-K3 are typical for Ethylene Propylene Rubber with the lines attributed to ethylene and propylene chain vibrations of macromolecules: symmetric and asymmetric stretch $v(\mathrm{C}-\mathrm{H})$ vibration lines at $2915,2852 \mathrm{~cm}^{-1}$ for $\mathrm{CH}_{2}$ and deformation $\delta(\mathrm{C}-\mathrm{H})$ vibrations in $\mathrm{CH}_{2}$ and $\mathrm{CH}_{3}$ groups at 1455 and $1361 \mathrm{~cm}^{-1}$ due to the presence of propylene group, skeletal complex shape of vibrations in wavenumber 1230 and $1000 \mathrm{~cm}^{-1}[6,7]$. The peak at $720 \mathrm{~cm}^{-1}$ indicates $\left(\mathrm{CH}_{2}\right)_{\mathrm{n}}-$ wagging vibration owing to the presence of polyethylene chain (Figure 3, time 0). The peak at $3417 \mathrm{~cm}^{-1}$ and the strong peak at $1014 \mathrm{~cm}^{-1}$ are attributed to the elongation of the SiO group [8].

Visible changes in the spectra of both samples after UV exposure can be recorded in the wavelength range from $1100 \mathrm{~cm}^{-1}$ to $1800 \mathrm{~cm}^{-1}$ after the first 24 hours. The peaks reduction observed in $2915 \mathrm{~cm}^{-1}$ and $2852 \mathrm{~cm}^{-1}$ can be attributed to the $\mathrm{CH}_{2}$ and $\mathrm{CH}$ bands.
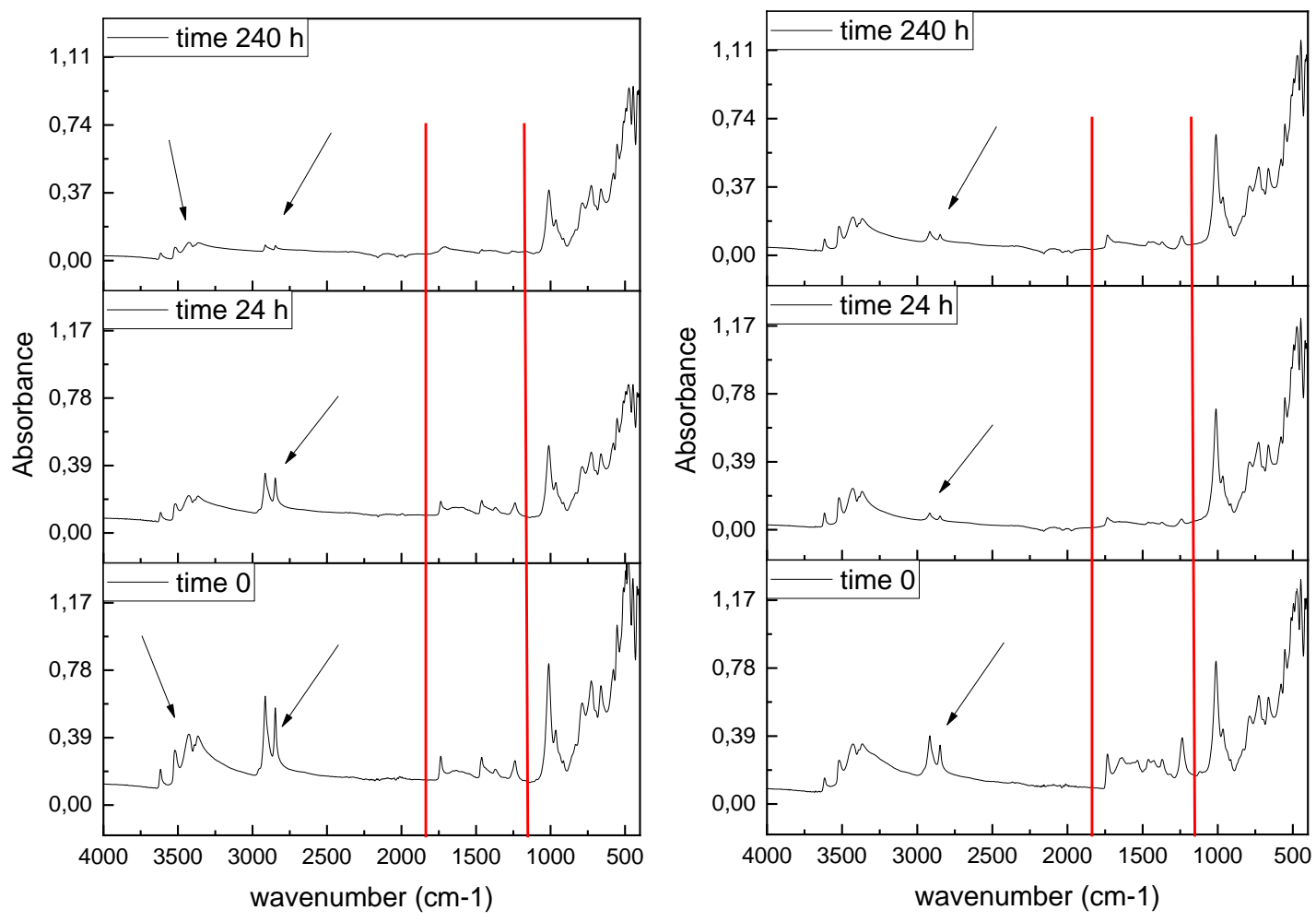

Figure 3 Effect of UV-C radiation on CHKE-V E30 and Nexans 273-K3

\section{Discolouration analysis}

All samples underwent an obvious colour change that was perceived visually as fading of the original colour. The $\Delta E^{*}$ value indicated the degree of colour change that was elevated. The untreated and treated samples were in all cases bigger and more noticeable after each 24 hours of exposure. 


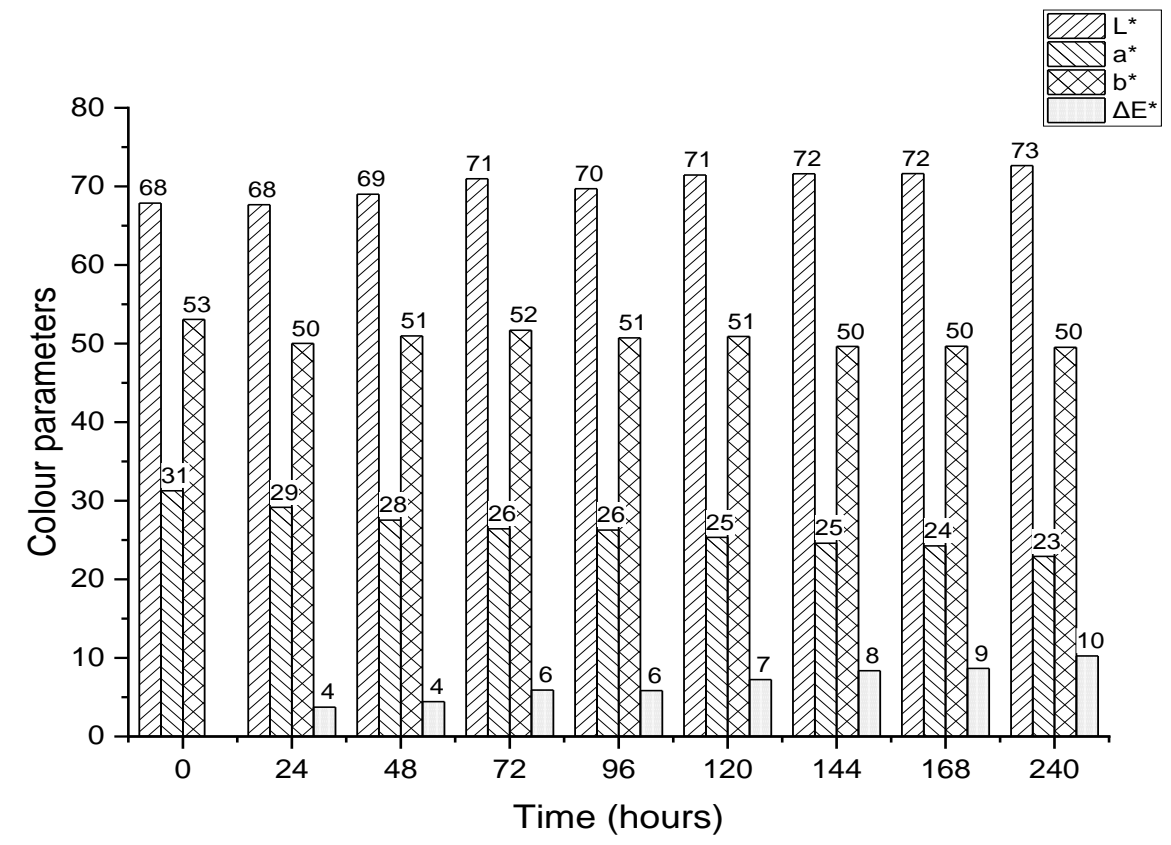

Figure 4 Effect of $U V$-C radiation on colour parameters of CHKE-V E3O

Figure 4 shows the effect of UV-C radiation on CHKE-V E30. A small change in all monitored parameters in time could be observed. $L^{*}$ which indicates a grey scale with increasing value, gets closer and closer to the white colour. Increasing values of $\Delta E^{*}$ indicated a bigger difference observable by the human eye.

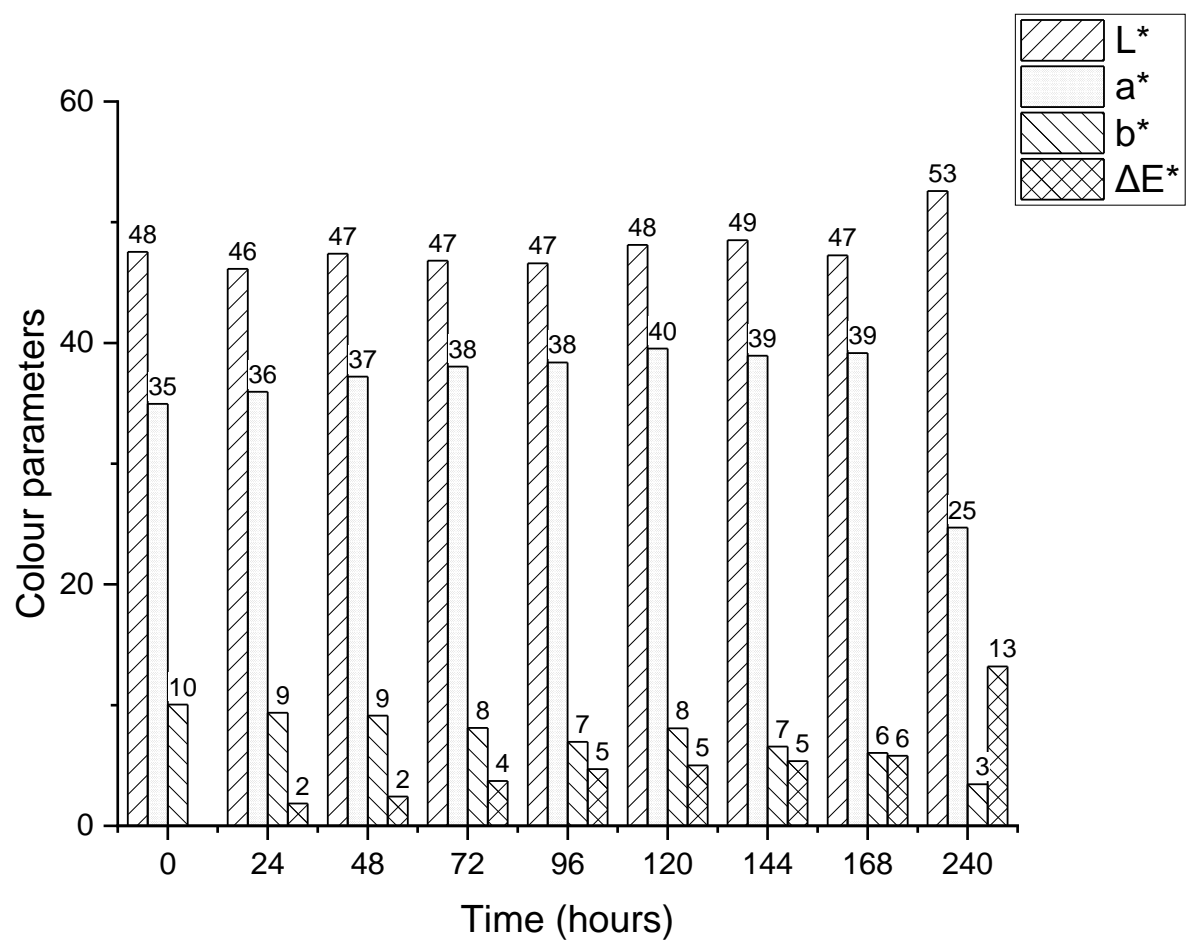

Figure 5 Effect of UV-C radiation on colour parameters of Nexans 273-K3

Figure 5 shows the effect of UV-C radiation on Nexans 273-K3. In this case, the change of colour parameters is also noticeable. The value of $L^{*}$ is increasing and values of $b^{*}$ are 
decreasing, which means that the green colour of Nexans 273-K3 becomes yellower. The rate of $\Delta E^{*}$ is greater than that of CHKE-V E30, the colour change was more significant.

This demonstrated that the UV-C treatment causes decolouration of polymers sample.

\section{The Shore Hardness}

Hardness values (Figure 6) show a little increase owing to the exposure to UV-C in both samples. Hardness is almost linear in relation to exposure time. The most significant increase of hardness in relation to that shown without exposure of UV-C is approximately $17 \%$ on the 6th day and $7 \%$ on the 7 th for Nexans $273-\mathrm{K} 3$, CHKE-V E30 respectively.
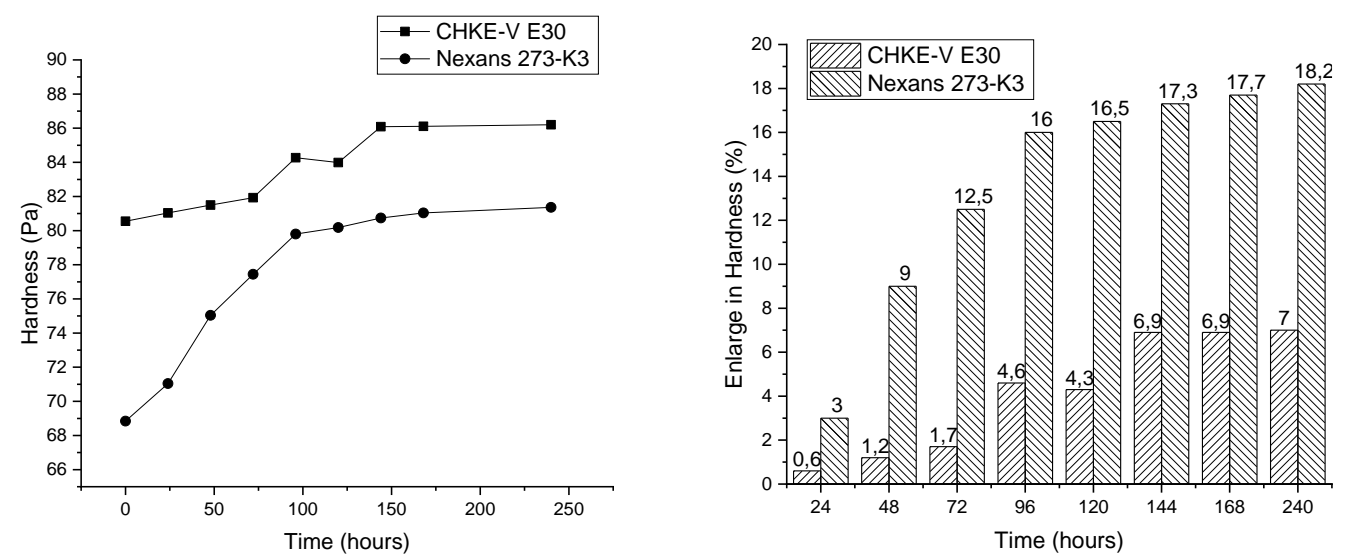

Figure 6 Effect of $U V$ radiation on hardness

Due to the longer exposure, no significant change was observed. It can be stated that the effect of UV-C radiance to samples CHKE-V E30 was slightly bigger in the sample of Nexans 273-K3.

\section{CONCLUSION}

Determining the safe life of polymeric materials is essential for their successful use in many areas. Ultraviolet (UV) radiation is one of the most destructive limitations that affect the properties of the material used to insulate electrical cables. It is clear from this study that exposure of the sheaths of the power cable to UV-C radiation caused a considerable photodegradation damage in a short time. This photodegradation damage was caused mainly on the surface of the insulation, as the penetration capacity of UV radiation is very low, i.e. $75 \mu \mathrm{m}$. The manifested changes in mechanical properties and chemical composition could be caused by the cracking of the bonds and subsequent crosslinking of the polymers in the surface layer. This change in the internal arrangement would correspond to the research of Hedir A., who confirmed the deteriorating insulation properties of the insulations due to UV radiation. A more pronounced degrading effect could be owing to the combined effect of several external influences.

\section{Acknowledgments}

The research was supported by the Slovak Research and Development Agency under the contract No. APVV-16-0223. 


\section{References}

[1] A. PLOTA, A. MASEK. 2020. Lifetime prediction methods for degradable polymeric materials - a short review. Materials (Basel)., 13(20), pp. 1-25, 2020, doi: $10.3390 / \mathrm{ma1} 3204507$.

[2] K. S. SCHMITZ. 2017. Physical Chemistry, Reaction Rates and Mechanisms. Elsevier, pp. 695-760. ISBN 9780128005149. https://doi.org/10.1016/B978-0-12-800514-9.010014

[3] A. ZANCHET, A. MASIERO, F. D. B. DE SOUSA, R. N. BRANDALISE. 2019. The influence of UV-accelerated aging process on industrial waste containing EPDM. Recycling, 4(2), pp. 8-10. doi: 10.3390/recycling4020025.

[4] D. IRVING, D. A. LAMPROU, M. MACLEAN, S. J. MACGREGOR, J. G. ANDERSON, M. H. GRANT. 2016. A comparison study of the degradative effects and safety implications of UVC and $405 \mathrm{~nm}$ germicidal light sources for endoscope storage. Polym. Degrad. Stab., Vol. 133, pp. 249-254. doi: 10.1016/j.polymdegradstab.2016.09.006.

[5] E. C. AZEVEDO, E. M. NASCIMENTO, G. O. CHIERICE, S. CLARO, AND C. M. LEPIENSKI. 2013. UV and Gamma Irradiation Effects on Surface Properties of Polyurethane Derivate from Castor Oil. Polímeros Ciência e Tecnol., 23(3), pp. 305-311, doi: 10.4322/polimeros.2013.087.

[6] S. GUNASEKARAN, R. K. NATARAJAN, AND A. KALA. 2007. FTIR spectra and mechanical strength analysis of some selected rubber derivatives. Spectrochim. Acta - Part A Mol. Biomol. Spectrosc., 68(2), pp. 323-330. doi: 10.1016/j.saa.2006.11.039.

[7] T. H. MOKHOTHU, A. S. LUYT, AND M. MESSORI. 2014. Reinforcement of EPDM rubber with in situ generated silica particles in the presence of a coupling agent via a solgel route. Polym. Test., Vol. 33, pp. 97-106. doi: 10.1016/j.polymertesting.2013.11.009.

[8] M. VADIVEL, M. SURESH, C. KUMAR, C. VEDHI, V. SELVAM, J. DHAVEETHU RAJA. 2015. National Conference On Recent Trends And Developments. Sustainable Green Technologies, pp. 3-6. [Online]. Available: www.jchps.com.

\section{ORCID}

$\begin{array}{ll}\text { Alica Pastierová } & 0000-0003-1442-9652 \\ \text { Peter Godovčin } & 0000-0003-4531-417 X\end{array}$ 